\title{
A High Gain Microstrip Patch Array for 5 GHz WLAN Applications
}

\author{
B. W. Ngobese ${ }^{1}$, P. Kumar ${ }^{2 *}$ \\ ${ }^{1,2}$ Discipiline of Electrical, Electronic and Computer Engineering, \\ University of KwaZulu-Natal, King George V Avenue, Durban-4041, South Africa \\ *corresponding author, E-mail: pkumar_123@yahoo.com
}

\begin{abstract}
This paper presents the design, fabrication and measurement of a high gain 4-elements linear patch array, which uses the corporate feed technique with inset for excitation resonating at $5.216 \mathrm{GHz} . \mathrm{FR}-4$ is used as a dielectric substrate for the proposed array structure. The designed array is simulated and optimized by using CST microwave studio software. The element of the array is designed using the transmissionline model equations. The ground plane is made defective by incorporating slots and the reflective ground is utilized to enhance the gain of the array. The simulated and measured results for various parameters of the array are presented. The comparison between simulated and measured results show good agreement with little deviation. The optimized dimensions of the proposed design provides a maximum gain of $9 \mathrm{~dB}$ and a maximum directivity of $12.81 \mathrm{dBi}$. The antenna has been designed for the range $5.15-5.35 \mathrm{GHz}$ which is one of the ranges for $5 \mathrm{GHz}$ band for wireless local area networks (WLAN) applications as the IEEE 802.11 standard states.
\end{abstract}

\section{Introduction}

The characteristics such as simple in construction, compact in size, low cost in fabrication etc make microstrip antennas suitable for various applications such as mobile communications, radar applications, aircraft systems, etc. The rectangular and circular patch antennas are the most common patch configurations and suitable for many applications [1-2]. Circular polarizations [3], dual polarization [4-5], dual frequency operation [6], broad bandwidth [7], feed line flexibility [1] and beam scanning [2] can be easily obtained from these patch antennas. There are many favorable characteristics of microstrip antennas, however these antennas suffer with the major limitations of low gain and narrow bandwidth [1].

Researchers are continuously working to improve the gain characteristics and have proposed various techniques to improve the gain of the microstrip patch antennas. In [8], the multilayer substrate is used to improve the performance of the antenna. The maximum gain of $9.5 \mathrm{~dB}$ was achieved. In [9] a high gain E-shaped microstrip antenna is designed for high speed wireless networks. In this antenna, the patch is covered by a radome and the antenna is fed by an electromagnetically coupled and the designed antenna provides the maximum gain of $11 \mathrm{dBi}$. In [10], the design of a dual stacked high gain microstrip antenna is proposed.
Using stacked patches the gain bandwidth for above $8 \mathrm{~dB}$ is increased by $40 \%$. In [11], authors have presented an Eshaped dual band patch antenna with the maximum gain of $10.37 \mathrm{~dB}$ at $1.84 \mathrm{GHz}$. The design of a high gain microstrip antenna for the radio frequency wireless power transfer and energy harvesting applications is presented in [12]. The thick substrate is used to enhance the gain of the proposed antenna and a gain of $4.14 \mathrm{~dB}$ gain is achieved. The directivity of the microstrip antennas can also be enhanced by operating in higher order mode than in fundamental mode [13-15]. Patch antenna arrays have lot of gain performance improvement compared to single patch antennas, this fact about the patch antenna arrays makes them very popular in applications where high gain is required [1-2].

This paper deals the gain enhancement using the array and slots in the ground plane which is separated from the reflective layer by the spacers with medium as air. The design and development of 4-elements microstrip antenna array is presented. The simulated and measured results have been presented and analyzed. The achieved maximum gain and directivity of the presented array are $9.019 \mathrm{~dB}$ and $12.81 \mathrm{dBi}$, respectively. The designed and developed array is suitable for $5 \mathrm{GHz}$ WLAN applications. Rest of the paper is organized as follows. Section 2 presents the proposed array design, geometrical configuration of the array and the dimensions of the array. The simulated and measured results are discussed in section 3. Finally, section 4 concludes the work.

\section{Proposed array design}

This section presents the design procedure of the proposed array. The most commonly used rectangular patch is chosen as the element of the array. The array is fed by using a corporate feed network to maintain the constant behavior of the pattern of the array as the path travelled by the signals in each path is same and the phased difference between the elements are not dependent upon the frequencies. Corporate feed network with inset at each patch to match the input impedance properly by adjusting the inset position $y_{o}$, is employed to feed the antenna because it gives the design power over each element of the network thus making it easy to optimize the parameters in order to get the required results. Initially, the element of the array is designed. In the next step, a $2 \times 1$ array is designed. After $2 \times 1$ array design, the $4 \times 1$ array is designed and finally using the concept of slots in the ground plane and the reflected layer is used to 
design the high gain array. Each step of the array design is discussed below.

The rectangular patch array element is designed for 5 $\mathrm{GHz}$ WLAN frequency band. The method of analysis used to analyze the patch elements and the entire array is the transmission line model due to its simplicity. The design equations of the rectangular patch are given below [1].

The width of the patch $(W)$ is computed by [1]:

$$
W=\frac{c}{2 f_{r}} \sqrt{\frac{2}{\varepsilon_{r}+1}}
$$

Where c, $f_{r}$ and $\varepsilon_{r}$ are the speed of light, resonant frequency and dielectric constant of the substrate, respectively. Considering the fringing effect, the effective dielectric constant $\left(\varepsilon_{\text {reff }}\right)$ and the actual length of the patch $(L)$ are computed by [1]:

$$
\begin{aligned}
& \varepsilon_{\text {reff }}=\frac{\varepsilon_{r}+1}{2}+\frac{\varepsilon_{r}-1}{2 \sqrt{1+\frac{12 h}{W}}} \\
& L=L_{\text {eff }}-2 \Delta L=\frac{c}{2 f_{r} \sqrt{\varepsilon_{\text {reff }}}}-2 \Delta L
\end{aligned}
$$

where

$$
\Delta L=\frac{h(0.412)\left(\left(\varepsilon_{r e f f}+0.3\right)\left(\frac{W}{h}+0.264\right)\right)}{\left(\varepsilon_{\text {reff }}-0.258\right)\left(\frac{W}{h}+0.8\right)}
$$

Where $h$ is the thickness of the substrate. The substrate height $h$, dielectric constant $\varepsilon_{r}$ and resonant frequency $f_{r}$ are chosen to be $1.5 \mathrm{~mm}, 4.4$ and $5.25 \mathrm{GHz}$, respectively. The designed element is shown in Fig. 1.

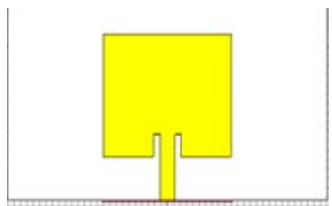

Figure 1: Element of the array

In the $2 \times 1$ array design, firstly the feeding network is designed and optimized. The designed feeding network is used to feed the patches as shown in Fig. 2. Here matching of individual patches to $100 \Omega$ is done, since the T-junction $(Z 1=Z 2+Z 3=2 * Z 2=2 * Z 3$, where $Z 1$ is the stem of the junction) is employed so that the entire array can be easily matched to $50 \Omega$. The designed $2 \times 1$ array is optimized to meet the specifications.

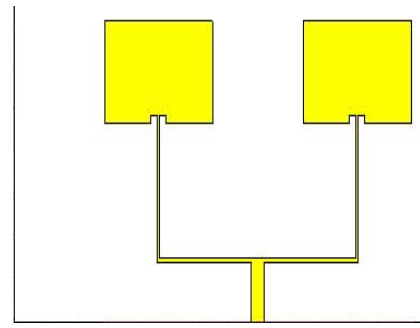

Figure 2: 2x1 patch antenna array schematic

The $2 \times 1$ array design concept is extended to design $4 \times 1$ array. In this design, the feed network of $2 x 1$ patch antenna array is first appended by the quarter wavelength section to convert $50 \Omega$ of the $2 \times 1$ array input strip line to $100 \Omega$ and dimensions are optimized. The two $2 x 1$ antenna array feed networks are combined using a T-junction and again optimized to achieve the reflection coefficient as per the standards and the input impedance matching to $50 \Omega$. The entire array is designed and optimized further in order to fulfil the specifications of this design project. The quarter wave line has a length of $\frac{\lambda}{4}$ and the width of $1.61 \mathrm{~mm}$ which corresponds to $70.7 \Omega$.

Gain increases with the decrease in the side lobe level of the patch antenna, the decrease in side lobe level is achieved by using the two techniques as explained here. The circular slots in the middle of the patches on the ground plane are inserted and the effect of the radius on the gain and resonant frequency is analyzed. The variation of gain and resonant frequency with the radius of slots is shown in Fig. 3. From Fig. 3, it is observed that the gain and resonant frequency increase upon increasing the radius of the slot. Considering the resonant frequency for $5.15 \mathrm{GHz}$, the maximum possible radius for maximum gain is $2 \mathrm{~mm}$.

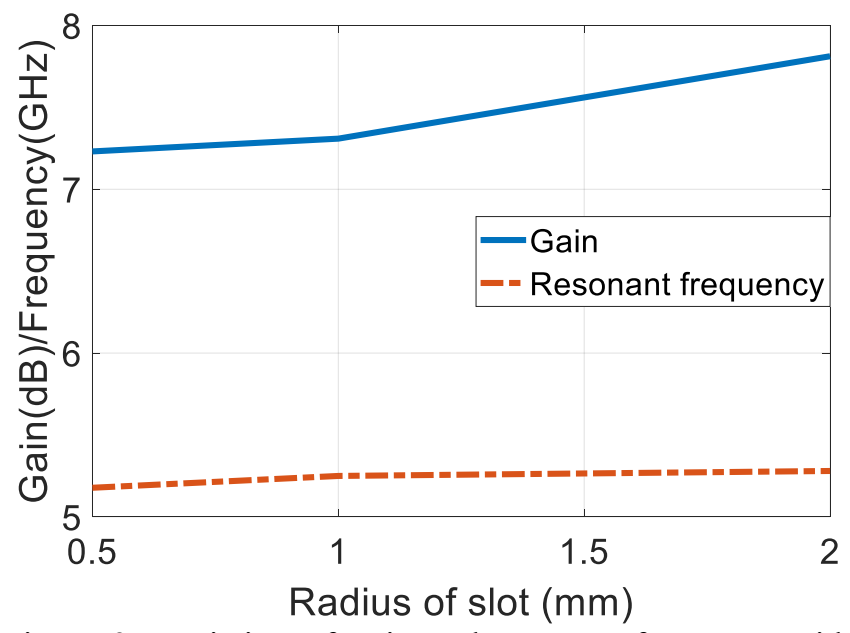

Figure 3: Variation of gain and resonant frequency with radius of slot.

To enhance the gain further a reflecting layer of same substrate material and thickness covered by copper of $0.035 \mathrm{~mm}$ is added to the patch array to redirect the side lobes and back lobes back to the main lobe. The reflecting layer helps with the strengthening of the main lobe by redirecting the radiation in the undesired direction back to the main lobe. Spacers used in simulation are the FR-4 spacers. The effect of the spacers length on the gain and resonant frequency is analyzed. The variation of the gain and resonant frequency with spacers length is shown in Fig. 4. From Fig. 4, it can be observed that the resonant frequency is independent from spacers length and the optimum value of spacers length for maximum gain is 7.98 $\mathrm{mm}$

For the optimum value of the spacers length, the effect of the radius of the slots upon the reflection coefficient is studied and shown in Fig. 5. It can be observed that the resonant frequency decreases upon increasing the radius of slots. The resonant frequency of the array is $5.3 \mathrm{GHz}, 5.25$ $\mathrm{GHz}, 5.2 \mathrm{GHz}, 5.13 \mathrm{GHz}$ and $5.06 \mathrm{GHz}$ for the slot radius 1 $\mathrm{mm}, 1.5 \mathrm{~mm}, 2 \mathrm{~mm}, 2.5 \mathrm{~mm}$ and $3 \mathrm{~mm}$, respectively. 


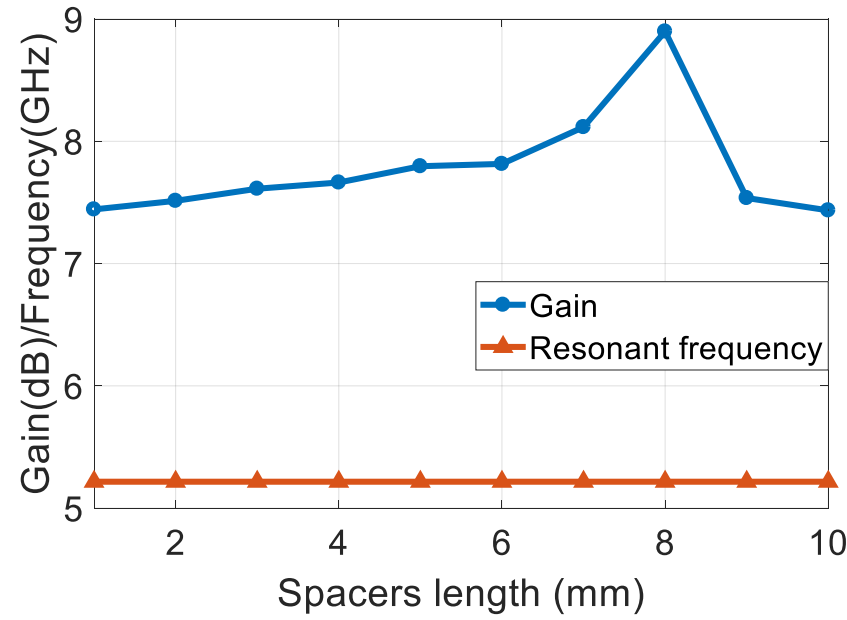

Figure 4: Variation of gain and resonant frequency with spacers length (radius of slot $=2 \mathrm{~mm}$ )

Further, the effect of slot radius upon gain at various frequencies are investigated and presented in Fig. 6. From Fig. 6, it is observed that the gain increases with increase in radius of slot significantly for lower frequencies, however there is small decrease in the gain for some part of higher frequency range. So, considering the resonant frequency shifting and gain variation with radius of slots the optimum value for radius of slot for the specified frequency range is 2 $\mathrm{mm}$. However, the gain of the array can be increased further for lower frequency design.

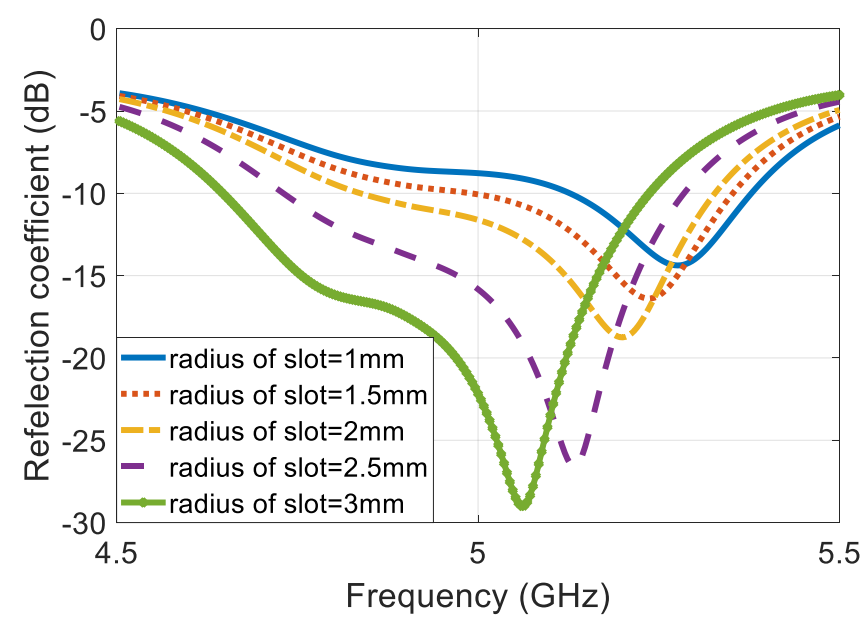

Figure 5: Reflection coefficient of the array for various radius of slots (spacers length $=8 \mathrm{~mm}$ ).

The geometry of the proposed $4 \times 1$ array with high gain is presented in Fig. 7. The top view, side view, ground plane with circular slots and the combined overall array are shown in Fig. 7(a), Fig, 7(b), Fig. 7(c) and Fig. 7(d), respectively. The proposed design is optimized using CST microwave studio. The detailed optimized dimensions of the structure are given in Fig. 7 (a) and is summarized in Table 1.

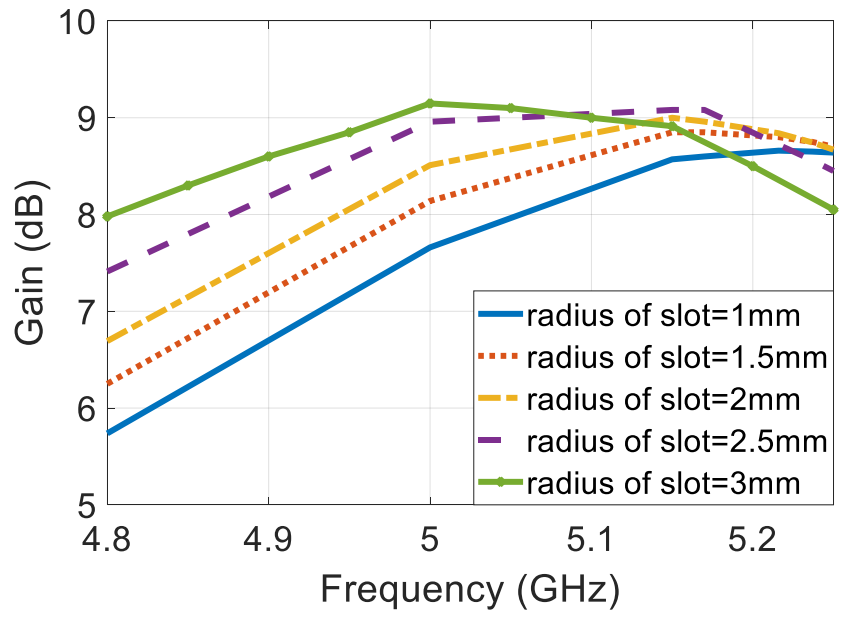

Figure 6: Variation of gain and resonant frequency with spacers length (spacers length $=8 \mathrm{~mm}$ ).

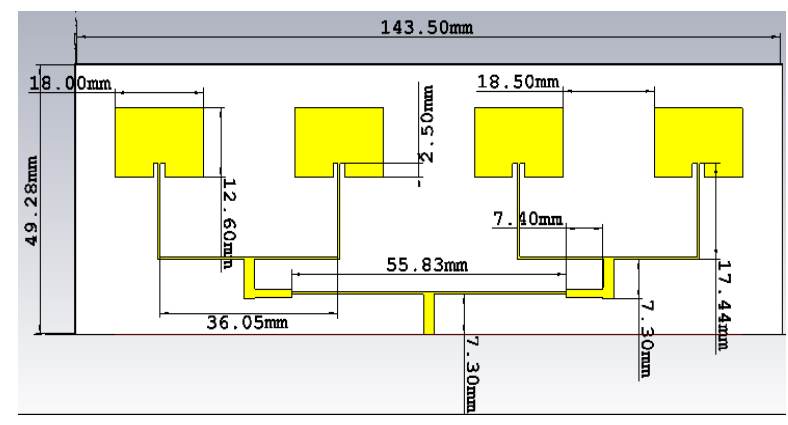

(a) Top view

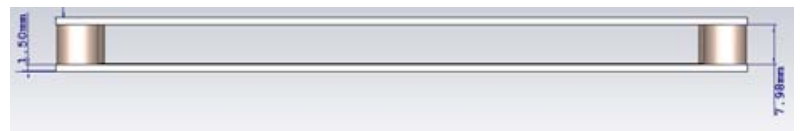

(b) Side view

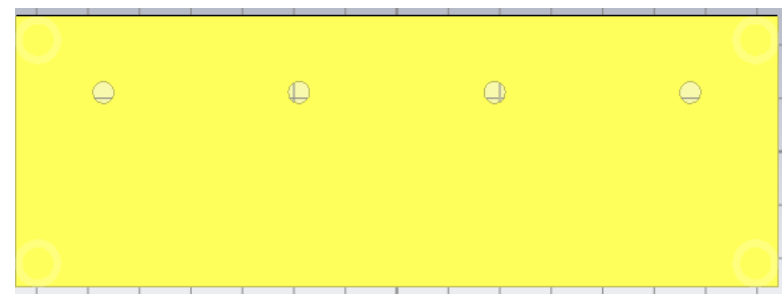

(c) Ground plane with circular slots

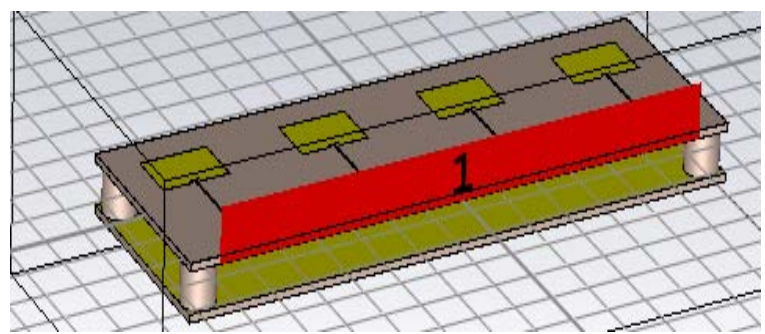

(d) The combined overall array comprising a reflecting layer

Figure 7: Geometry of the proposed array, (a) top view, (b) side view, (c) ground plane with circular slots, (d) the combined overall array comprising a reflecting layer. 
Table 1: Optimized dimensions.

\begin{tabular}{ccc}
\hline $\begin{array}{c}\text { S. } \\
\text { No. }\end{array}$ & $\begin{array}{c}\text { Dimension } \\
\text { parameter }\end{array}$ & Value \\
\hline 1 & Length of the patch & $18 \mathrm{~mm}$ \\
2 & Width of the patch & $12.6 \mathrm{~mm}$ \\
3 & Radius of slots & $2 \mathrm{~mm}$ \\
4 & Spacers length & $7.98 \mathrm{~mm}$ \\
5 & Thickness of the & $1.5 \mathrm{~mm}$ \\
& $\begin{array}{c}\text { substrate } \\
6\end{array}$ & Dielectric constant \\
of the substrate & 4.4 \\
\hline
\end{tabular}

\section{Fabrication, results and discussion}

The array with optimized dimensions is fabricated and measured. To test the antenna using the probe, an SMA connector is soldered on the patch's input strip line and ground plane. The images of the fabricated array are show in Fig. 8. The top view, ground plane layer with circular slots and the combined array are shown in Fig. 8(a), Fig. 8(b) and Fig. 8(c), respectively.

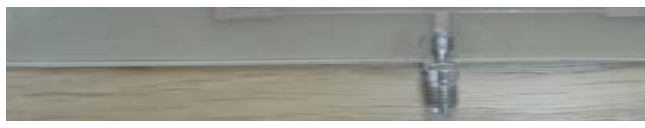

(a) Top layer

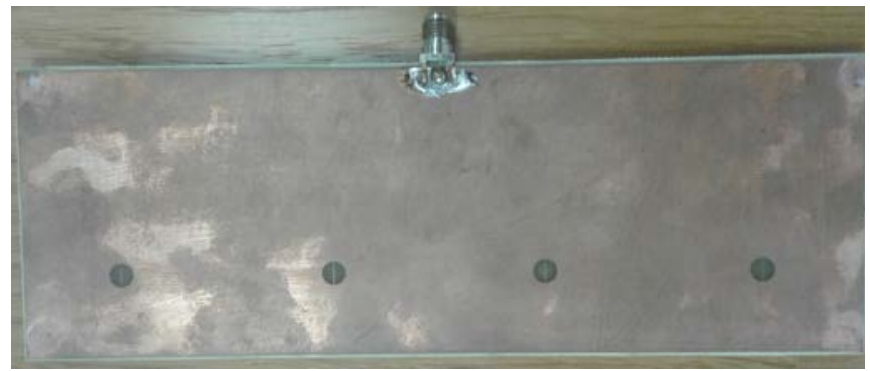

(b) Ground plane layer with circular slots.

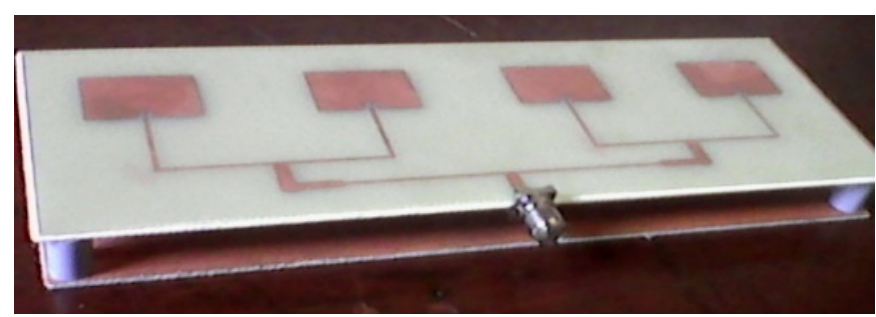

(c) The combined array

Figure 8: Photographs of the patch array prototype and measurement setup, (a) top layer, (b) ground plane with slots, (c) the combined overall array.
The simulated and measured reflection coefficient of the proposed array is shown in Fig. 9. The simulated reflection coefficient is less than $-10 \mathrm{~dB}$ for the frequency range from $4.8 \mathrm{GHz}$ to $5.3 \mathrm{GHz}$, hence the bandwidth of the designed array is $4.8 \mathrm{GHz}-5.3 \mathrm{GHz}$. The little deviation in the measured and simulated results are possibly due to the connector and dielectric losses as well as the resolution limitation of the fabrication machine.

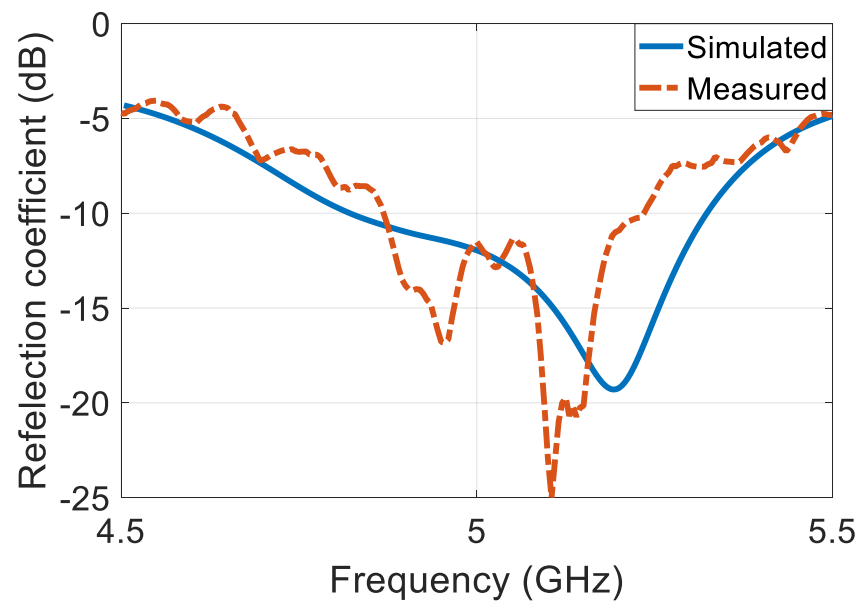

Figure 9: Reflection coefficient of the proposed array.

The simulated radiation patterns of the array is shown in Fig. 10. The 3D gain pattern at $5.15 \mathrm{GHz}$, the normalized patterns in $\emptyset=0^{\circ}$ plane at $5 \mathrm{GHz}$ and $5.15 \mathrm{GHz}$, the normalized patterns in $\emptyset=0^{\circ}$ plane at $5.25 \mathrm{GHz}$ and 5.35 $\mathrm{GHz}$, the normalized patterns in $\varnothing=90^{\circ}$ plane at $5 \mathrm{GHz}$ and $5.15 \mathrm{GHz}$, the normalized patterns in $\emptyset=90^{\circ}$ plane at $5.25 \mathrm{GHz}$ and $5.35 \mathrm{GHz}$ are shown in Fig. 10(a), Fig. 10(b), Fig. 10(c), Fig. 10(d) and Fig. 10(e), respectively. From these figures, it is observed that the pattern in $\emptyset=0^{\circ}$ plane have narrow beam as compared to $\varnothing=90^{\circ}$ plane. The direction of the main beam is constant for the entire frequency range. The cross polarization level is very low in all radiation patterns. The simulated gain and directivity of the array at various frequencies are depicted in Table 2. From Table 2, it can be observed that the efficiency of the array is low and it is due to dielectric losses in lossy FR4 substrate. In the case of array, the signals travel for long path in the dielectric as compared to antenna and the substrate is of bigger size in the structure of array, hence losses are more. The efficiency of the array can be improved by using other dielectric substrate with low loss. The maximum gain of $9.0 \mathrm{~dB}$ at $5.15 \mathrm{GHz}$ and the maximum directivity of 12.81 $\mathrm{dBi}$ at $5.15 \mathrm{GHz}$ are achieved by the proposed array. The designed and developed high gain array is suitable for 5 $\mathrm{GHz}$ WLAN applications. 


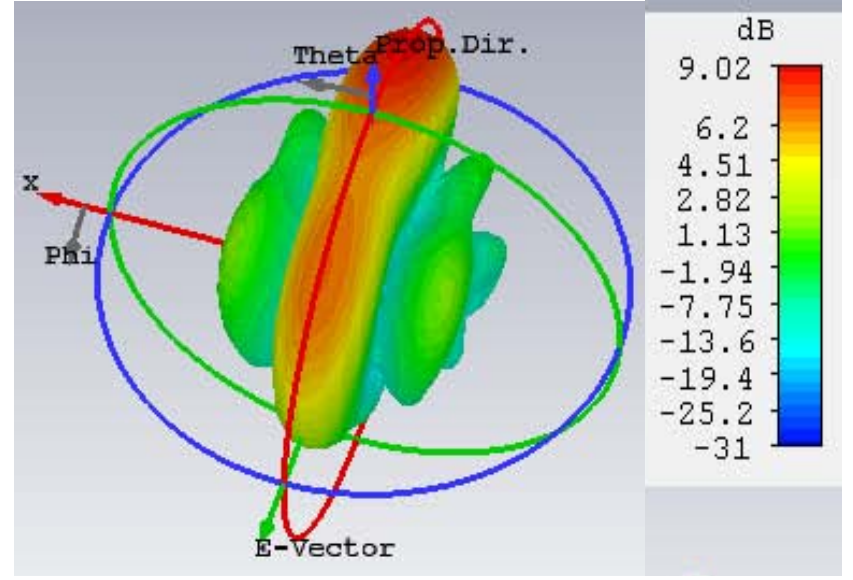

(a) $3 \mathrm{D}$ at $5.15 \mathrm{GHz}$

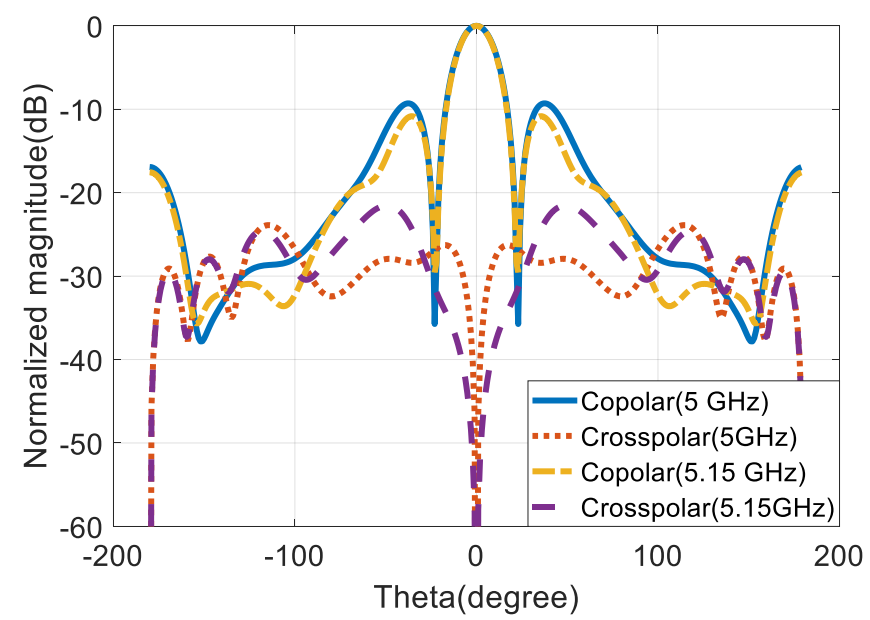

(b) $\varnothing=\mathbf{0}^{\circ}$ plane at $5 \mathrm{GHz}$ and $5.15 \mathrm{GHz}$

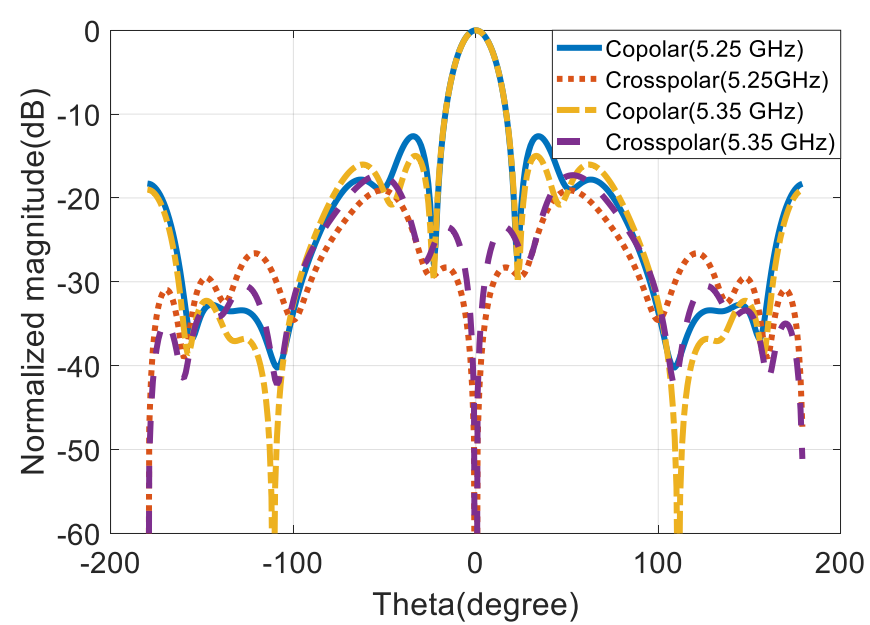

(c) $\varnothing=0^{\circ}$ plane at $5.25 \mathrm{GHz}$ and $5.35 \mathrm{GHz}$

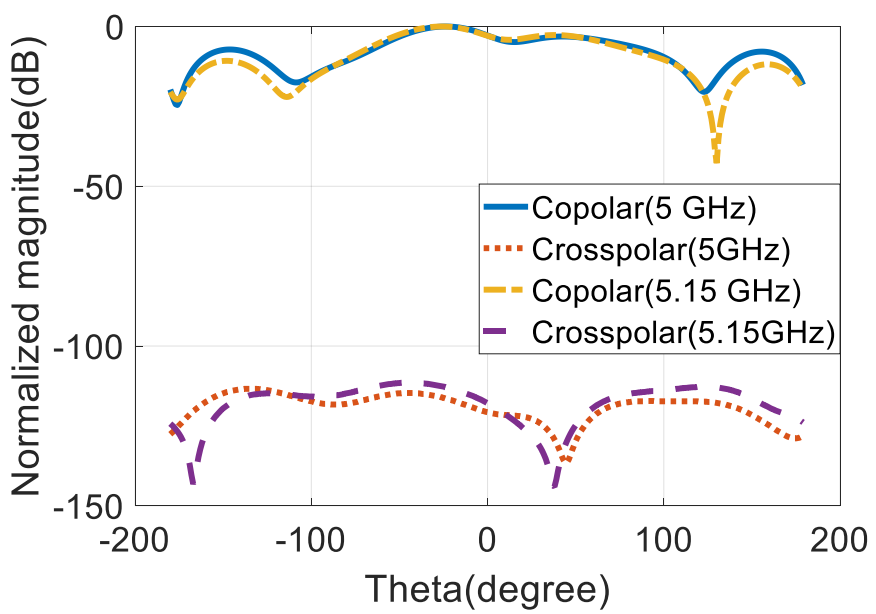

(d) $\varnothing=90^{\circ}$ plane at $5 \mathrm{GHz}$ and $5.15 \mathrm{GHz}$

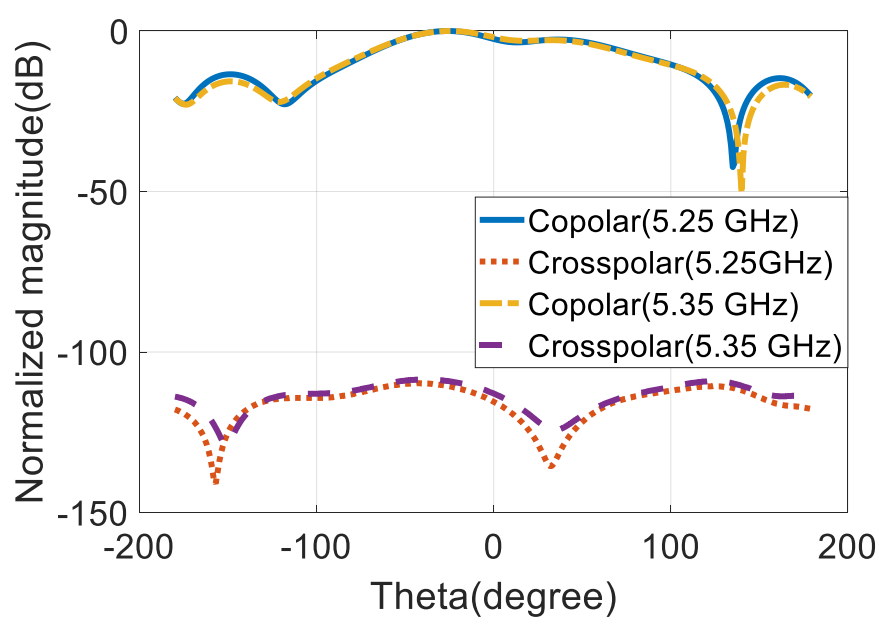

(e) $\varnothing=90^{\circ}$ plane at $5.25 \mathrm{GHz}$ and $5.35 \mathrm{GHz}$

Figure 10: Radiation patterns of the array (a) in $3 \mathrm{D}$ at 5.15 $\mathrm{GHz}$, (b) in $\emptyset=0^{\circ}$ plane at $5 \mathrm{GHz}$ and $5.15 \mathrm{GHz}$, (c) in $\emptyset=0^{\circ}$ plane at $5.25 \mathrm{GHz}$ and $5.35 \mathrm{GHz}$, (d) in $\emptyset=90^{\circ}$ plane at $5 \mathrm{GHz}$ and $5.15 \mathrm{GHz}$, (e) in $\varnothing=90^{\circ}$ plane at 5.25 $\mathrm{GHz}$ and $5.35 \mathrm{GHz}$.

Table 2: Max. gain and max. directivity of the array.

\begin{tabular}{cccc}
\hline $\begin{array}{c}\text { S. } \\
\text { No. }\end{array}$ & Frequency & $\begin{array}{c}\text { Max. } \\
\text { gain } \\
(\mathrm{dB})\end{array}$ & $\begin{array}{c}\text { Max. } \\
\text { directivity } \\
(\mathrm{dBi})\end{array}$ \\
\hline 1 & $4.8 \mathrm{GHz}$ & 6.76 & 11.74 \\
2 & $5.0 \mathrm{GHz}$ & 8.56 & 12.48 \\
3 & $5.15 \mathrm{GHz}$ & 9.0 & 12.81 \\
4 & $5.2 \mathrm{GHz}$ & 8.90 & 12.79 \\
5 & $5.3 \mathrm{GHz}$ & 8.32 & 12.67 \\
\hline
\end{tabular}

\section{Conclusion}

A high gain four element linear patch array has been designed, fabricated and measured in this paper. The gain of the array is enhanced by utilizing the slots in the ground plane and the reflected ground plane. The design is simulated and optimized. The optimized structure is 
fabricated and measured. The simulated and measured results are presented. The comparison between measured and simulated results show good agreement with little deviation. The presented array covers the frequency range of $5 \mathrm{GHz}$ WLAN. The maximum gain and maximum directivity of the presented array are $9.019 \mathrm{~dB}$ and 12.81 $\mathrm{dBi}$, respectively and the cross polarization is very low. The presented array is suitable for $5 \mathrm{GHz}$ wireless local area networks applications.

\section{Acknowledgements}

Authors acknowledge their gratitude to the reviewers for their valuable comments and suggestions for improving quality of manuscript. Authors also acknowledge their gratitude to University of KwaZulu-Natal for providing financial support and laboratory facilities for this work.

\section{References}

[1] C. A. Balanis, Antenna theory: analysis and design, $3^{\text {rd }}$ ed, John Wiley \& Sons, Hoboken, New Jersey, 2005.

[2] R. Garg, P. Bhartia, I. Bahl, A. Ittipiboon, Microstrip Antenna Design Handbook, Artech House Publi 5 Boston, London, 2001.

[3] S. Ahmed, Z. Zakaria, M. N. Husain and M. Abu, Microstrip antenna design with circular polarization property for RF energy harvesting application, International Journal of Applied Engineering Research, 11(6): 4398-4401, 2016.

[4] P. Kumar, J. L. Masa-Campos, Dual polarized monopole patch antennas for UWB applications with elimination of WLAN signals, Advanced Electromagnetics, 5(1): 46-52, 2016.

[5] P. Kumar, J. L. Masa-Campos, A novel dual polarized waveguide fed circular patch antenna for $\mathrm{Ku}$ band applications, Microwave and Optical Technology Letters, 59(7): 1743-1750, 2017.

[6] I. Ali, R. Y. Chang, Design of dual-band microstrip patch antenna with defected ground plane for modern wireless applications, Proceedings of 2015 IEEE 82nd Vehicular Technology Conference, 1-5, 2015.

[7] E. K. I. Hamad and N. Mahmoud, Compact tri-band notched characteristics UWB antenna for WiMAX, WLAN and X-band applications, Advanced Electromagnetics, 6(2): 53-58, 2017.

[8] T. A. Denidni and L. Talbi, High gain microstrip antenna design for broadband wireless applications, Wiley Periodicals Inc, 511-517, 2003

[9] T. A. Denidni and N. Hassaine, Q. Rao, Broadband and high-gain E-shaped microstrip antennas for high-speed wireless networks" Progress In Electromagnetics Research C, 1: 105-111, 2008.

[10] N. Ghassemi, J. Rashed-Mohassel, M. H. Neshati, S. Tavakoli, M. Ghassemi, "A high gain dual stacked aperture coupled microstrip antenna for wideband applications", Progress In Electromagnetics Research B, 9: 127-135, 2008.
[11] N. Keskin, S. Kandemir, H. Hizarcıŏlu and T. İmeci, E-shaped high gain microstrip patch antenna, Proceeding of 28th Annual Review of Progress in Applied Computational Electromagnetics, 946-951, 2012.

[12] C. A. Di Carlo , L. Di Donato, G. S. Mauro, R. La Rosa, P. Livreri and G. Sorbello, A circularly polarized wideband high gain patch antenna for wireless power transfer, Microwave and Optical Technology Letters, 60: 620-625, 2018.

[13] J. Anguera, C. Puente, C. Borja, R. Montero, and J. Soler, "Small and high directivity bowtie patch antenna based on the sierpinski fractal", Microwave and Optical Technology Letters, 31 (3): 239-241, 2001.

[14] J. Anguera, J. P. Daniel, C. Borja, J. Mumbrú, C. Puente, T. Leduc, N. Laeveren, and P. V. Roy, "Metallized foams for fractal-shaped microstrip antennas", IEEE Antennas and Propagation Magazine, 50 (6): 20-38, 2008.

[15] J. Anguera, A. Andújar, S. Benavente, J. Jayasinghe, and S. Kahng, "High-directivity microstrip antenna with mandelbrot fractal boundary", IET Microwaves, Antennas \& Propagation, 12 (4): 569-575, 2018. 